Tropical Journal of Pharmaceutical Research, December 2003; 2 (2): 235-238

(C) Pharmacotherapy Group,

Faculty of Pharmacy, University of Benin,

Benin City, Nigeria

All rights reserved.

Available online at http://www.tjpr.freehosting.net

Research Article

\title{
Comparative in-vitro studies on the efficacy of ivermectin against gastrointestinal sheep nematode
}

\author{
Isaiah O Ademola ${ }^{1 \Phi}$ Benjamin O Fagbemi ${ }^{1}$ Olakunle S Idowu ${ }^{2}$ \\ ${ }^{1}$ Department of Veterinary Microbiology and Parasitology, and ${ }^{2}$ Department of Pharmaceutical Chemistry, Faculty of \\ Pharmacy, University of Ibadan, Ibadan, Nigeria
}

\begin{abstract}
Purpose: This study was designed to evaluate the relative efficacy of various brands of ivermectin injection available for use in clinical veterinary practice in Nigeria.

Method: Ivermectin injections were evaluated by a larval development assay (LDVA), using the larvae of Strongyles (predominantly Haemonchus contortus) of sheep. The effect of standard solutions of the drug from the various brands on the transformation of $L_{1}$ to $L_{3}$ and survival of $L_{3}$ larvae was used to assess bioactivity. The $50 \%$ lethal concentration ( $\left.L C_{50}\right)$ was determined from regression line obtained by probit transformation of the biological data. The $L C_{50}$ values for each of the brands were compared with that of the innovator brand (Ivomec Super ${ }^{\circledR}$ ) for any significant difference.

Results: The $L C_{50}$ values obtained for the five brands varied widely. It ranges from $1.1 \pm 0.17$ $\mathrm{ng} / \mathrm{ml}$ for the innovator brand to $2.3 \pm 0.3,3.0 \pm 0.3,8.0 \pm 0.2$ and $17.0 \pm 0.3 \mathrm{ng} / \mathrm{ml}$ for the other four brands. The biological assays performed on each of the five brands were of comparable precision. $L C_{50}$ for IVomec super ${ }^{\Theta}$ was significantly different from those of the other four brands (Student's $t$ test, $p<0.01$ ).

Conclusion: The bioactivities of brands of ivermectin injections available in Nigeria are significantly different. This is a probable reason for the varied treatment response to various brands of ivermectin injection in veterinary practice in Nigeria. This justifies the need for drug regulatory bodies in Nigeria to ensure that ivermectin injections registered for use in Nigeria meets approved standards before the drugs are allowed to be imported into the country.
\end{abstract}

Key words: Bioactivity, ivermectin, sheep nematode

${ }^{\Phi}$ To whom correspondence should be addressed: E-mail: adejanet@yahoo.com Tel: +234-2-8107551 


\section{Ademola et al., 2003}

\section{Introduction}

Ivermectin is an analogue of avermectin, which belongs to a family of 16-membered macrocyclic lactones. It is known to increase membrane permeability to chloride ions possibly as a result of their interaction with chloride ion channels ${ }^{1}$. Its broad spectrum of activity and wide safety margin has made it the drug of choice for nematode and arthropod parasitism in cattle, sheep, goat, swine and horses ${ }^{2}$. However, farmers and clinicians in Nigeria have observed wide variation in treatment response with different brands of Ivermectin injection against endoand ecto-parasites of animals. This often results in poor helminth control and sometimes treatment failure, with the consequent economic loss.

The availability of different formulations of the injection from various manufacturers warrants the comparative evaluation of bioactivity of the various brands in Nigerian market. In this paper therefore, we describe the comparative anthelmintic activity of various brands of ivermectin injection against gastrointestinal nematode of sheep, using a larval development assay.

\section{Materials and Methods}

\section{Nutritive medium}

The nutritive medium was as described by Hubert and Kerboeuf ${ }^{4}$. It is composed of Earle's balance salt solution plus yeast extract diluted in saline solution (1 gm yeast extract in $90 \mathrm{ml}$ of saline solution).

\section{Preparation of ivermectin solution}

The ivermectin injection brands investigated are Iverject ${ }^{\circledR}$ (Batch No. 349590, Special T. Product, UK), Ivomec Super ${ }^{\circledR}$ (Batch No. HN 00270, MSD, Merial, Netherlands), Kepromec $^{\circledR}$ (Batch No. OlJ15, Kepro B.V, Holland), Ivojec (Batch No. 2001.12, Sinochem Ningbo, China), and Ivermectin ${ }^{\circledR}$ (Batch No. 2531, Anupco, UK). Appropriate

\section{Ivermectin and sheep nematodes}

aliquots of these drugs were taken from different stock aqueous solutions (1000 $\mathrm{ng} / \mathrm{ml}, 100 \mathrm{ng} / \mathrm{ml}$ and $10 \mathrm{ng} / \mathrm{ml}$ ) of drug prepared from the injection (apart from Ivomec super ${ }^{\circledR}$ which contains $10 \%$ clorsulon in addition to the ivermectin labeled content, the other brands of ivermectin injections contain $1 \% \mathrm{w} / \mathrm{v}$ solution of ivermectin in propylene glycol). The final concentration in the assay tubes were over the range of $0.2-60.0 \mathrm{ng} / \mathrm{ml}$ of ivermectin.

\section{Nematode Egg Recovery Technique}

The technique used was that previously described by Prichard ${ }^{3}$. Briefly, 10-15 $\mathrm{g}$ of faeces of sheep was suspended in water and cleared of organic debris by filtration through sieves $(1 \mathrm{~mm}$ and $100 \mu \mathrm{m})$ and the eggs were collected on a $20 \mu \mathrm{m}$ sieve. These eggs were further cleared from organic debris by centrifugation in magnesium sulphate (density 1.10) for $5 \mathrm{~min}$ at $1000 \mathrm{~g}$. The supernatant was filtered through $100 \mu \mathrm{m}$ and $60 \mu \mathrm{m}$ sieves and the eggs were washed in water and collected on a $20 \mu \mathrm{m}$ sieve.

The concentration of eggs was estimated in $50 \mu \mathrm{l}$ samples and adjusted to $100-120$ eggs $/ \mathrm{ml}$. The egg suspension was diluted with the filtrate from the first step of egg extraction (described above) in order to provide rumen bacteria necessary for nematode larvae development. To avoid the proliferation of fungi, $5 \mu \mathrm{g}$ of amphotericin B was added per $\mathrm{ml}$ of egg suspension.

\section{Larval development viability assay (LDVA)}

Using a $5-\mathrm{ml}$ test tube, $150 \mu \mathrm{l}$ of nutritive medium was added to $50 \mu \mathrm{l}$ of egg suspension containing approximately 100 eggs. Three replicates per concentration or water (control) were made. The tubes were covered and put in an incubator at $29^{\circ} \mathrm{C}$, for $48 \mathrm{hr}$ to allow development of the parasite to first stage larvae. Appropriate aliquots of the drug was then added. The third stage larvae 


\section{Ademola et al., 2003}

were obtained seven days later. At this time, the parasite was counted by separating the larvae in to two classes, living third stage larvae $\left(\mathrm{L}_{3}\right)$ and dead larvae. Larval development parameter is given by:

No. of Living $L_{3} /$ total no. of nematode in tubes with anthelmintic divided by no. of living $L_{3}$ /total number of nematode in control tube (water).

\section{Statistical analysis}

Data from LDVA were transformed by probit transformation and plotted against the logarithm of concentration ${ }^{7}$. Probit transformation was performed to transform a typical sigmoid dose-response curve to a linear function. The concentration required to kill $50 \%$ of $\mathrm{L}_{3}\left(\mathrm{LC}_{50}\right)$ was calculated from this linear regression scale.

Relative bioactivity of the various brands was determined by comparing the mean $L_{50}$ of each of the other brands with the $\mathrm{LC}_{50}$ for Ivomec Supe using a Student $t$-test (2-tailed) at 95\% confidence interval. Probability $(p)$ values $<0.01$ was considered to be significant ${ }^{5}$.

\section{Results and Discussion}

A linear relationship was observed between larval survival and drug concentration for the various brands of ivermectin injection (Figure 1). The calculated $L C_{50}$ of Iverject, Ivomec super, Kepromec, Ivojec and Ivermectin were $2.3 \mathrm{ng} / \mathrm{ml}, 1.1 \mathrm{ng} / \mathrm{ml}, 8.0 \mathrm{ng} / \mathrm{ml}, 17.0$ $\mathrm{ng} / \mathrm{ml}$ and $3.0 \mathrm{ng} / \mathrm{ml}$, respectively. The result of the comparison of the bioactivity of the various injection brands with Ivomec super is as shown in the Table 1.

The results show variation in the bioactivity (LC ${ }_{50}$ ) of the brands of Ivermectin injection investigated, ranging from $1.1 \mathrm{ng} / \mathrm{ml}$ to 17 $\mathrm{ng} / \mathrm{ml}$. In a previous work, Ademola ${ }^{6}$ reported varying $L_{50}(0.79-4.0 \mathrm{ng} / \mathrm{ml})$ for Ivomec MSD against strongyles of sheep from different farms in Oyo State, Nigeria. In
Ivermectin and sheep nematodes

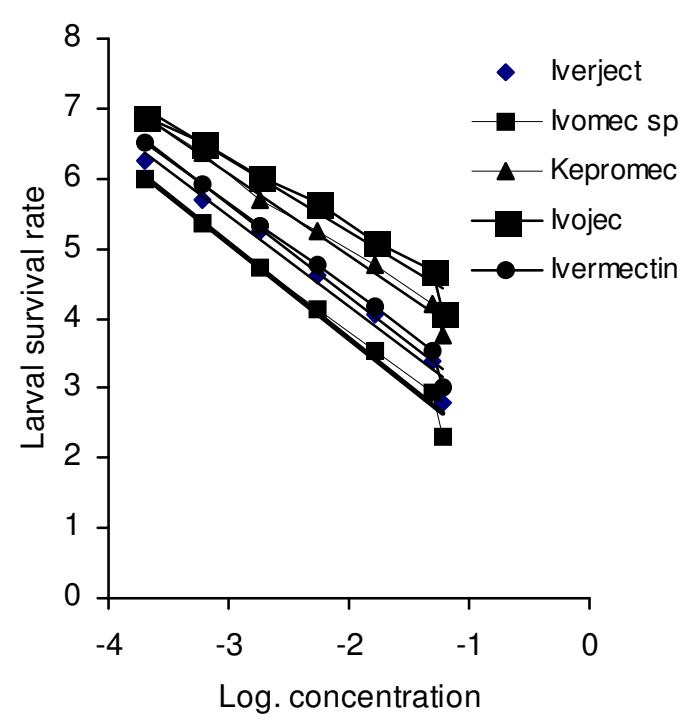

Figure 1: Linear relationship between mean values of live $L_{3}$ (on a probit) of strongyles following a 7 day incubation period in ivermectin injection brands and ivermectin concentration. Each point represents the mean of three replicates.

Table 1: Comparison of the bioactivity of ivermectin injection brands with Ivomec super.

\begin{tabular}{lll}
\hline Injection brands & $\mathrm{LC}_{50}(\mathrm{ng} / \mathrm{ml})$ & $\mathrm{p}$-value \\
\hline 1. Ivomec super & $1.1 \pm 0.2^{*}$ & \\
2. Iverject & $2.3 \pm 0.3$ & $<0.01$ \\
3. Ivermectin & $3.00 \pm 0.3$ & $<0.01$ \\
4. Kepromec & $8.0 \pm 0.2$ & $<0.01$ \\
5. Ivojec & $17.0 \pm 0.3$ & $<0.01$ \\
\hline
\end{tabular}

$*$ Reference product

another report', it was shown that Weybridge strain of Haemonchus contortus is more susceptible $\left(\mathrm{LC}_{50}-0.4 \mathrm{ng} / \mathrm{ml}\right)$ than the Australian strain $\left(\mathrm{LC}_{50}-8.9 \mathrm{ng} / \mathrm{ml}\right)$ to ivermectin (Ivomec MSD). An ivermectin resistant strain of $H$. contortus was also reported to have $\mathrm{LC}_{50}$ of $8.0 \mathrm{ng} / \mathrm{ml}^{8}$.

The strongyles used for this present work are from a mixed infection naturally acquired by sheep, and were identified to be 


\section{Ademola et al., 2003}

predominantly $H$. contortus. Ivomec MSD is the innovator company's brand and it showed the highest activity $\left(\mathrm{LC}_{50}=1.1\right.$ $\mathrm{ng} / \mathrm{ml})$. However, it contains clorsulon in addition to the ivermectin active ingredient. The latter is reported (in the package insert) to be specific anthelmintic for liver fluke. It is possible that this combination could enhance the activity of ivermectin against other nematodes.

Ivomec super was selected as the reference brand for estimating bioactivity of the other brands because it is the innovator brand. When compared with other products, the $\mathrm{LC}_{50}$ for Ivomec super was significantly different $(p<0.01)$. This implies that the bioactivity of this product is significantly different from this reference product. Results of this study could explain the variation in treatment response often reported by clinicians prescribing these different brands of ivermectin. Significant difference in the bioactivity of the brands is a reflection of the difference in the quality these drug products being marketed by different manufacturers. The biologic inequivalence of the different brands shown by this in vitro study could be due to differences in the formulation of the products or chemical compositions.

\section{Conclusion}

The results of this study show that the brands of ivermectin injection investigated are not bioequivalent. This could explain why different brands of ivermectin injection may show variation in treatment responses.

\section{Ivermectin and sheep nematodes}

An investigation of the chemical equivalence of the brands by a physicochemical assay method is warranted in order to provide supportive data that could further explain the differences in the $\mathrm{LC}_{50}$ obtained. The results underscore the need for post market surveillance of drugs intended for veterinary use after initial registration by drug regulatory authorities.

\section{References}

1. Turner MJ, Schaeffer JM. Mode of action of Ivermectin. In: Campbell WC (ed). Ivermectin and Abamectin. New York, USA: Springer, 1989 pp 73-8.

2. Campbell WC, Fisher MH, Stapley EO, AlbertSchonberg G, Jacobs TA. Ivermectin: a potent new antiparasitic agent. Science. 1983: 22 : 823-8.

3. Prichard RK. Interaction of host physiology and efficacy of antiparasitic drug. Vet Parasitol. 1985; 18: 103-10.

4. Hubert J, Kerboeuf, D " Nutritive medium for invitro culture of Nematode larvae. Can $\mathrm{J}$ Comp Med. 1984; 48: 63

5. Bailey NTJ. Statistical Methods in Biology, $2^{\text {nd }}$ ed. Cambridge, UK: Cambridge University Press, 1981 pp 90-8

6. Ademola IO. A survey on ivermectin resistance in strongyles of sheep in Oyo Sate, Nigeria using Larval Development Assay. Israel J Vet Med. 2002: 57(4): 149-51.

7. Hubert J, Kerboeuf D. A microlarval development assay for the detection of anthelmintic resistance in sheep nematodes. Vet Record. 1992; 130: 442-6.

8. Taylor MA. A larval development tests for the detection anthelmintic resistance in nematode of sheep. J Vet Sci. 1990; 49: 198-202 